\title{
Resveratrol: A Sirtuin Activator and The Fountain of Youth
}

\author{
Anna Meiliana ${ }^{1,2, *}$, Nurrani Mustika Dewi², Andi Wijaya ${ }^{2,3}$ \\ ${ }^{1}$ Postgraduate Program in Clinical Pharmacy, Padjadjaran University, Jl. Eijkman No.38, Bandung, Indonesia \\ ${ }^{2}$ Prodia Clinical Laboratory, Jl. Cisangkuy No.2, Bandung, Indonesia \\ ${ }^{3}$ Postgraduate Program in Clinical Biochemistry, Hasanuddin University, Jl. Perintis Kemerdekaan Km.10, Makassar, Indonesia \\ *Corresponding author. E-mail: anna.meiliana@prodia.co.id
}

\section{Abstract}

B ACKGROUND: An organism's lifespan is inevitably accompanied by the aging process, which involves functional decline, a steady increase of a plethora of chronic diseases, and ultimately death. Thus, it has been an ongoing dream of mankind to improve healthspan and extend life.

CONTENT: There are only a few proposed aging interventions: caloric restriction, exercise, and the use of low-molecular-weight compounds, including spermidine, metformin, resveratrol, and rapamycin. Resveratrol, a constituent of red wine, has long been suspected to have cardioprotective effects. Interest in this compound has been renewed in recent years, first from its identification as a chemopreventive agent for skin cancer, and subsequently from reports that it activates sirtuin deacetylases and

\section{Introduction}

For thousands of years humanity has searched for the fountain of youth. In the $16^{\text {th }}$ century the Spanish explorer Juan Ponce de León, first Governor of Puerto Rico, searched for the fountain of youth in the legendary land of Florida, specifically in the waters of Bimini, but without success. This quest continues, although all living species on our planet are designed to age. A fountain-of-youth strategy has been proposed by several investigators during recent decades. This strategy to slow down the aging processes is based on caloric restriction (CR) and increased physical activity.(1)

The reduction in the intake of calories without malnutrition is defined as CR. Such reduction ideally extends the lifespans of lower organisms. Resveratrol have been shown to prevent and reduce the severity of age-related diseases such as atherosclerosis, stroke, myocardial infarct, diabetes, neurodegenerative diseases, osteoarthritis, tumors and metabolic syndrome, along with their ability to extend lifespan.

SUMMARY: The purpose of aging research is the identification of interventions that may avoid or ameliorate the ravages of time. In other words, the quest is for healthy aging, where improved longevity is coupled to a corresponding healthspan extension. It is only by extending the healthy human lifespan that we will truly meet the premise of the Roman poet Cicero: "No one is so old as to think that he may not live a year."

KEYWORDS: aging, caloric restriction, mimetic, healthspan, sirtuin activator

Indones Biomed J. 2015; 7(1): 1-14 corresponds to a decrease of approximately $30 \%$ of calories per day, at least in mice. In humans, there is some indication that a CR of around 15\% may be most favorable against mortality during aging.(2) One of the best correlations between $\mathrm{CR}$ and improvement in healthspan and prolonged life in humans is the long-lived population in Okinawa, Japan.(3) In comparison to the rest of the Japanese population, Okinawan people usually combine an aboveaverage amount of daily exercise with a below-average food intake.(2) However, when Okinawan families moved to Brazil, they adopted a Western lifestyle that impacted both their diet and physical activity, resulting in increased weight gain and a drop in life expectancy of 17 years.(3) CR changes many parameters in the aging human body, including the transcriptome, the hormonal status (in particular the serum concentration of Insulin-like Growth Factor (IGF)- 
1 and thyroid hormones), oxidative stress, inflammation, mitochondrial function, and glucose homeostasis. $(4,5)$

Recent discoveries, however, have focused attention towards interesting molecules able to increase lifespan and prevent age-related diseases. These molecules are called sirtuin (SIRT). The mammalian SIRT 1-7 belong to a family of histone deacetylases, named for their homology to the Saccharomyces cerevisiae gene silent information regulator (Sir)2. SIRT require nicotinamide adenine dinucleotide $\left(\mathrm{NAD}^{+}\right)$as a cofactor to deacetylate substrates ranging from histones to transcriptional regulators.(6) An increasing number of studies clearly reported that activation of SIRT, especially SIRT1 and SIRT3, increases longevity by mimicking the beneficial effects of CR. Moreover, recent findings have suggested that moderate prolonged exercise training is able to increase SIRT1 activity in aged animals, counteracting age-related dysfunctions.(7) Does taking SIRT's activators produce the same effect as drinking water from the legendary fountain of youth? This is the main question that several scientists worldwide are trying to answer.(1)

Resveratrol is a polyphenol that is found in grapes and in red wine. Its potential to promote lifespan was first identified in yeast (8), and it has since gained fame because it was suggested to be responsible for the so-called French paradox (French winemakers do not suffer from cardiovascular diseases though enjoying a high-fat diet) (5). Overall, it is clear that resveratrol treatment or SIRT1 overexpression prevents several age-associated diseases and pathogenic conditions, including oxidative stress in the aging heart, neurodegeneration, or diabetes.(9) Importantly, activation of autophagy by resveratrol is required for lifespan extension in Caenorhabditis elegans (C. elegans). $(5,10)$

\section{Aging and Age-related Diseases}

The more complex a problem, the more important it may be to ask simple questions. So, why do we age? Actually, we do hold the capacity for immortality. The molecular clock in our germline stem cells, which sustain gamete production, is kept at zero as evidenced by the fact that our offspring are not born with the father's or mother's age. Then why do somatic cells age? First, the maintenance of repair activity in all our cells represents a vast energetic demand and, second, the pressure of recombination and dying of generations allows organisms to adapt to changing environments (e.g., ice ages). This implies that aging may be an atavistic, adaptive and altruistic program, by which single cells or organisms eventually die for the benefit of the whole population in a highly coordinated (programmatic) fashion.(5)

A hallmark of aging is compromised tissue maintenance.(11) Tissue-specific stem cells self-renew and persist throughout an organism's lifespan to repair and maintain tissues. The self-renewal potential and differentiation capacity of stem cells become dysregulated with age. $(12,13)$ Stem cell aging is thought to be due to cumulative cellular and genomic damages, resulting in permanent cell-cycle arrest, apoptosis, or senescence.(1214) A major source of cellular damage is reactive oxygen species (ROS), a natural by-product of cellular respiration. (15) ROS levels in stem cells increase dramatically with age.(16) Deficient intracellular management of ROS results in increased stem cell cycling and apoptosis, as well as compromised self-renewal and differentiation, resembling essential aspects of aged stem cells.(17-21)

The study by Brown, et al. provides important insights into mitochondrial metabolism in stem cell maintenance and illuminates the previously underappreciated plasticity of mitochondrial homeostasis in stem cell maintenance and tissue homeostasis during the aging process. Using oxidative stress as a readout for various mitochondrial processes regulated by SIRT3, they show that SIRT3mediated mitochondrial homeostasis is essential for HSC maintenance under stress and that this regulatory program is downregulated with age. Together, these data suggest that suppression of SIRT3-mediated mitochondrial homeostasis contributes to increased oxidative stress in aged hematopoietic stem cell (HSC). This regulatory process complements the view that passive accumulation of damaged mitochondria with age results in increased ROS and underlies the plasticity of mitochondrial homeostasis in stem cell maintenance and tissue homeostasis.(22)

According to the World Health Organization (WHO), age itself remains the greatest risk factor for all major lifethreatening disorders, and the number of people suffering from age-related diseases is anticipated to almost double over the next two decades. The fact that healthspan has not increased at the same pace as lifespan is a source of grave concern.(23) Both obesity and hypertension represent major risk factors for stroke and cardiovascular disease. Although weight loss and increase in physical activity are generally prescribed to avoid such age-associated diseases, only a small percentage of people have the discipline to change their lifestyle accordingly.(24) The prevalence of age-related pathologies represents major psychological and social impediments as well as an economic burden that urgently needs appropriate interventions.(5)

Over three quarters of deaths from cardiovascular 
diseases occur among patients over 65 years of age. (25) Epidemiological studies show that even in the absence of risk factors related to lifestyle (e.g., obesity, hypercholesterolemia, smoking), advanced age, per se, promotes the development of cardiovascular disease.(26) In order to develop novel therapeutic interventions to promote vascular health in older persons, it is essential to understand the mechanisms through which aging impairs homeostatic mechanisms in the vasculature.(27) Vascular oxidative stress and inflammation are thought to promote the development of atherosclerotic vascular diseases (including myocardial infarction, stroke, and vascular dementias), increasing cardiovascular mortality in elderly patients.(26)

Viewing the reality of aging from the arterial wall begins with the realization that arterial diseases, e.g. atherosclerosis and hypertension, are rampant in modern society, and increase exponentially with advancing age. Progressive changes occur throughout life in the structure and function of central arteries in numerous species. These changes include diffuse intimal and medial thickening, and enhanced stiffening.(28) Since the likelihood for predominantly systolic hypertension and atherosclerosis to occur increases in epidemic proportion among older persons. $(28,29)$ it is reasonable to hypothesize that specific mechanisms that underlie alterations in the arterial substrate that accompany "aging" may be intimately linked to the ageassociated exponential increase in predominantly systolic hypertension.(30)

Central arterial aging is a hallmark of systems aging, and can be viewed as the failure of key signaling pathways to execute crucial functions.(30) These aging related changes in the molecular and cellular functions of key signaling systems facilitate adverse central arterial remodeling, such as diffuse intima - media thickening, enhanced stiffening, and endothelial dysfunction.(28,31-33) Arterial wall aging begins with chronic proinflammation, a form of 'sterile-like' inflammation that occurs in the absence of any microorganisms and with little or no white blood cell infiltration. Phenotypic shifts in arterial endothelial cell and vascular smooth muscle cell (VSMC) promote pathogenic inflammation.(28,31-33) This is why arterial aging dwarfs other risk factors for clinical manifestations and severity of hypertension and atherosclerosis.(34)

\section{CR, Exercise and Mimetics}

Nutrition is among the most important means for mitigating age-associated chronic diseases. By some estimates, $80 \%$ of coronary heart disease (CHD) and type-2 diabetes mellitus and $40 \%$ of cancers may be prevented by modifying dietary habits, engaging in regular physical activity, and avoiding tobacco use.(35-37) The Okinawans are of special interest to this topic as they, by most measures, have the world's longest-lived population, and nutritional factors appear to have played a key role.(38-40) The chronic disease profile of the older Okinawan population is especially impressive, with $80 \%$ less CHD mortality and $40 \%$ less cancer mortality than the US population.(38) Some attribute the healthy aging phenomenon in Okinawa principally to nutritional factors, and CR is thought to be one key factor. $(38,39,41,42)$

$\mathrm{CR}$ is the only regimen known to extend the life span and health span in a spectrum of organisms that include yeast, mice, and nonhuman primates.(43-45) Reducing food consumption $25-60 \%$ without undernutrition extends the life span of rodents up to $50 \%$ (45) and in different animal models delays the onset of age-related maladies, like cardiovascular disease, cancer, and diabetes $(43,46)$. The positive effects of $\mathrm{CR}$ are linked to major metabolic reprogramming toward efficient fuel utilization and a reduction in oxidative damage to macromolecules. $(47,48)$ Long-term $\mathrm{CR}$ in humans inhibits the IGF-1/insulin pathway in skeletal muscle, a key metabolic tissue. CR also induces dramatic changes of the skeletal muscle transcriptional profile that resemble those of younger individuals. Finally, in both rats and humans, CR evoked similar responses in the transcriptional profiles of skeletal muscle. This common signature consisted of three key pathways typically associated with longevity: IGF-1/insulin signaling, mitochondrial biogenesis, and inflammation.(49)

Mitochondrial dysfunction plays an important role in cellular aging (50) and reduces fuel utilization plasticity. As metabolic centers for fuel utilization and primary producers of cellular ROS, mitochondria are poised to act as mediators of reprogramming under CR. However, the molecular basis for global metabolic adaptation induced by $\mathrm{CR}$ remains unknown.(51)

Fasting has been practiced for millennia, but, only recently, studies have shed light on its role in adaptive cellular responses that reduce oxidative damage and inflammation, optimize energy metabolism, and bolster cellular protection. In lower eukaryotes, chronic fasting extends longevity, in part, by reprogramming metabolic and stress resistance pathways. In rodents intermittent or periodic fasting protects against diabetes, cancers, heart disease, and neurodegeneration, while in humans it helps reduce obesity, hypertension, asthma, and rheumatoid arthritis. Thus, fasting has the potential to delay aging and help prevent and treat diseases while minimizing the side effects caused by chronic dietary interventions.(52) 
The traditional Okinawan diet is a rich source for potential CR mimetics. In the Okinawan language, the term "nuchi gusui", a term in common use, literally means 'food is medicine' as commonly consumed dietary items, including foods, herbs, and spices are also used as folk medicines.(53) Popular items that play dual roles as foods and traditional medicines are sweet potatoes (pulp, skin, and leaves), bitter melon, turmeric, ginger, mugwort (Artemisia vulgaris), peppers (Piper hancei), and carotenoid-rich marine foods, among others.(2) Compounds that have potential CR mimetic properties, such as carotenoids, flavonoids, and other phytochemicals, are synthesized (mostly by plants) to help scavenge-free radicals formed due to stress from extremes of heat, cold, or ultraviolet light. As the sun in Okinawa is particularly strong many locally grown plants contain high quantities of these phytochemicals.(54)

While CR increases lifespan, studies support more of a beneficial role for exercise on healthspan.(23) Although CR and exercise have similar effects, clearly disparities exist between these two interventions, with potential molecular mechanisms excellently reviewed by Huffman.(55) Despite not altering lifespan, regularly performed moderate exercise will delay certain age-associated changes and protect against several metabolic disorders.(56) Previous research has shown that exercise is associated with greater benefits than $\mathrm{CR}$, or vice versa. The most noticeable health benefits of exercise over CR are maintenance of aerobic capacity, muscle mass and muscle strength, and an improved bone health. $(57,58)$ As a consequence, regularly performed exercise has a stronger impact particularly in cardiovascular disease, diabetes and osteoporosis. Therefore, as pointed out by Huffman, et al., the effect of exercise may be more pronounced in humans, who perish more from cardiovascular disease, than in animal models that primarily die of renal disease or cancers.(59) Additionally, as aging is associated with a decline in physical activity, regular physical activity plays an essential role in the elderly by lessening disability and prolonging independent living.(60) Taken together, these findings provide compelling evidence that regularly performed exercise is associated with an improved quality of life, without slowing the aging process.(23)

\section{SIRT in Aging and Regeneration Medicine}

Sir2 family proteins, now called SIRT, have been demonstrated to coordinate metabolic responses to changes in nutritional availability and maintain physiological homeostasis in mammals.(61) These functions of SIRT are ascribed to their unique NAD-dependent enzymatic activities (62), placing SIRT at the perfect position to integrate energy metabolism information into many other biological regulations. In particular, the mammalian Sir2 ortholog SIRT1 plays a critical role for the regulation of metabolic responses in multiple tissues, including the liver, skeletal muscle, adipose tissue, and brain, through its deacetylase activity.(61) SIRT1 also plays a role in the regulation of phenotypes induced by $\mathrm{CR}$, a diet regimen

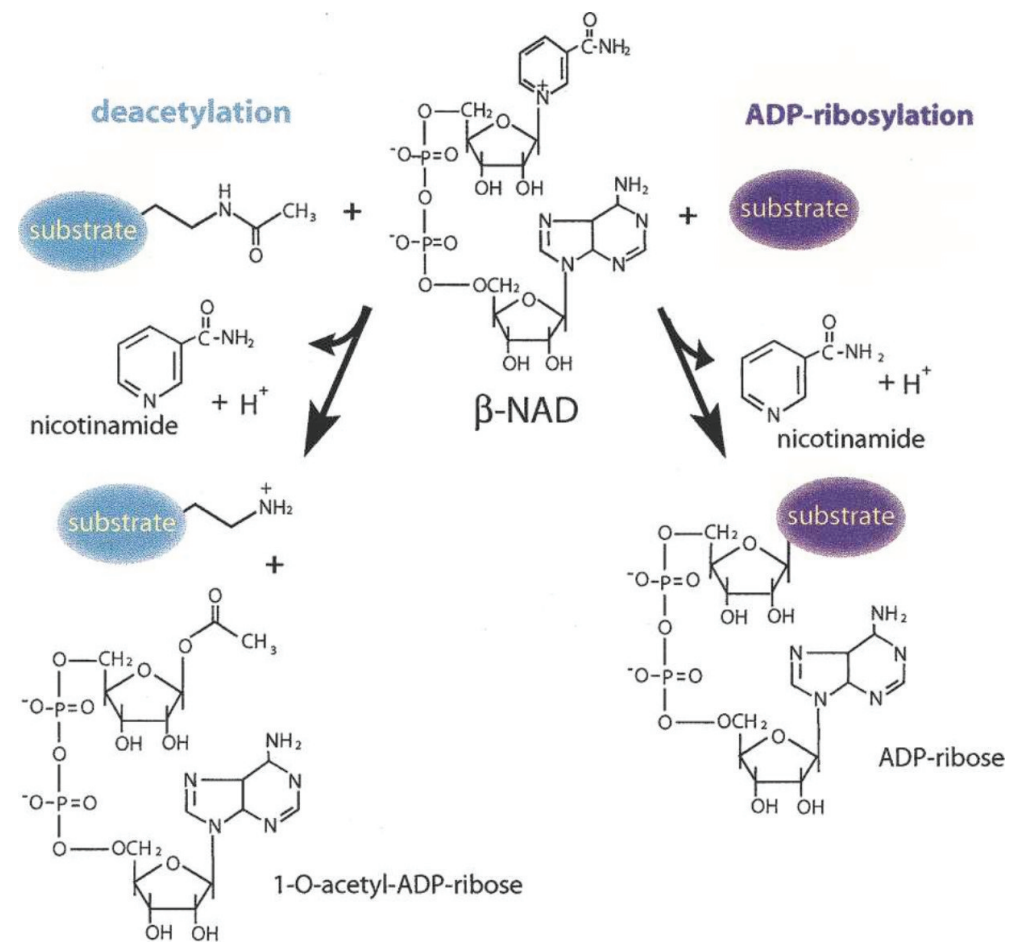

Figure 1. SIRT deacetylation and ADP-ribosylation reactions. Both deacetylation and ADP-ribosylation occur via cleavage of NAD to release nicotinamide. (9) (Adapted with permission from Cold Spring Harbor Laboratory Press). 
that delays aging and extends life span in a wide variety of organisms.(61)

SIRT1 is the closest to yeast Sir2 in terms of sequence and enzymatic activity, and is also the most extensively studied mammalian SIRT having numerous known substrates, including peroxisome proliferator-activated receptor gamma coactivator 1-alpha (PGC-1 $\alpha$ ), nuclear factor kappa-light-chain-enhancer of activated B cells (NFkB), p53 and forkhead box O (FOXO)1.(63-66) SIRT1 is an important regulator of metabolism. SIRT1 upregulates mitochondrial biogenesis in several tissues, stimulates fat and cholesterol catabolism in liver, skeletal muscle and adipose tissue.(67) In addition, liver glucose metabolism is regulated by SIRT1 inducing the gluconeogenic genes, phosphoenolpyruvate kinase and glucose-6-phosphatase by forming a protein complex with PGC- $1 \alpha$ and hepatocyte nuclear factor (HNF) $4 \alpha$. Moreover, SIRT1 modulates the effects of PGC- $1 \alpha$ repression of glycolytic genes, glucokinase and pyruvate kinase, acting the adenosine monophosphate (AMP)-activated protein kinase (AMPK) as the prime sensor that translates this information into SIRT1-dependent deacetylation (68-70), and also seems to activate fatty acid oxidation systemically by promoting adiponectin synthesis (71). SIRT1 deficiency in mice results in hyperglycemia, oxidative damage and insulin resistance and deficient animals become obese and insulin resistant when chronically challenged with a $40 \%$ fat diet, developing hepatomegaly.(71-73)

Over the past decade, a number of evolutionarily conserved regulators and signaling pathways have been identified for the control of aging and longevity. These regulators and signaling pathways, including insulin/IGF1 signaling (IIS) (74), mammalian target of rapamycin (mTOR) signaling (75), and NAD-dependent SIRT (61), provide excellent probes to dissect complex hierarchical mechanisms that affect the aging process and longevity in each model organism. Recent studies in worms and flies have also suggested that systemic interplay between multiple tissues regulates aging and longevity.(76,77) In mammals, however, the complexity of tissue interplay is multiplied, and a blueprint for a systemic network regulating aging and longevity still remains elusive.

Alterations in $\mathrm{NAD}^{+}$levels have a powerful metabolic impact because it serves as an obligatory substrate for the deacetylase activity of the SIRT proteins.(78-80) The bestcharacterized mammalian SIRT is SIRT1, which controls mitochondrial function through the deacetylation of targets that include PGC-1 $\alpha$ and FOXO. $(81,82)$ The administration of $\mathrm{NAD}^{+}$precursors, such as nicotinamide mononucleotide
(83) or nicotinamide riboside (NR) (84), has proven to be an efficient way to increase $\mathrm{NAD}^{+}$levels and SIRT1 activity, improving metabolic homeostasis in mice.(85) Considering the intimate link between metabolism and longevity $(78,86)$, it was hypothesized that increasing $\mathrm{NAD}^{+}$levels may be sufficient to increase mitochondrial activity and extend lifespan (82).

Sir2 is an NAD-dependent deacetylase that connects metabolism with longevity in yeast, worms and flies. (9) Sir2 is required for lifespan extension by CR in yeast, worms, and flies.(87-89) In yeast, CR (0.5\% glucose), was previously shown to increase mitochondrial function and to up-regulate Sir2 activity. $(90,91)$ However, in this case, the mitochondrial activation is SIR2-independent, suggesting that it lies upstream of Sir2. A more severe CR regimen $(0.05 \%$ glucose $)$ extends yeast replicative lifespan by a different mechanism that is apparently independent of both Sir2 and mitochondrial respiration.(92,93)

Stem cells, through their regenerative ability, maintain tissue homeostasis during an individual's lifespan. However, stem cell-associated mechanisms of tissue repair become impaired with aging. Very interestingly, a recent study demonstrated that SIRT3, which is highly expressed in hematopoietic stem cells, is not essential for tissue repair at a young age under physiological conditions; however, it is crucial at an old age.(1) Moreover, it is important to highlight that induced SIRT3 overexpression, which is suppressed with aging, significantly improves aged hematopoietic stem cells' regenerative power.(22) The plasticity of mitochondrial homeostasis controlling stem cell and tissue maintenance during the aging process and shows that aging-associated degeneration can be reversed by a SIRT.(22)

\section{Therapeutic Potential of Resveratrol}

Resveratrol (3,5,4'-trihydroxystilbene) was first isolated from the roots of white hellebore (Veratum grandiflorum O. Loes) in 1940 (94), and later, in 1963 from the roots of Polygonum Cupsidatum, a plant used in traditional Chinese and Japanese medicine (95). However, the first real interest in this compound came when in 1992 resveratrol was postulated to explain some of the cardioprotective effects of red wine (96) and was suggested to be an important factor in the French Paradox, a term coined to describe the observation that the French population has a very low incidence of cardiovascular disease, despite a diet high in saturated fat (97). Five years later, in 1997, Jang 
and colleagues reported resveratrol to work as a chemopreventive agent, by the ability to inhibit carcinogenesis at multiple stages.(98) Meanwhile, also anti-inflammatory and anti-oxidant properties were identified for resveratrol. $(99,100)$ Interest in resveratrol peaked after 2003, when Howitz and colleagues (8) identified resveratrol as a potent SIRT1 activator capable of mimicking the effects of calorie restriction $(101,102)$ and regulating longevity in lower organisms, by extending lifespan in yeast (8), worms (103), flies $(104,105)$ and in short-lived fish (106). Although there are a considerable amount of data supporting the role for resveratrol in SIRT1-mediated lifespan extension.(107)

The exact mechanisms through which resveratrol exerts a wide range of beneficial effects across species and disease models is currently still unclear.(99) Similar to most other polyphenols, resveratrol is suggested to possess intrinsic anti-oxidant capacity, but it is also implicated to induce the expression of a number of antioxidant enzymes, with probably both mechanisms contributing to an overall reduction in oxidative stress.(108) Resveratrol further interacts with a large number of receptors, kinases, and other enzymes that could plausibly make a major contribution to its biological effects.(107)

In mammals, there is growing evidence that resveratrol can prevent or delay the onset of cancer, heart disease, ischaemic and chemically induced injuries, diabetes, pathological inflammation and viral infection. These effects are observed despite extremely low bioavailability and rapid clearance from the circulation.(99)

Resveratrol provides diverse health benefits including cardioprotection, inhibition of low-density lipoprotein, activation of nitric oxide (NO) production, hindering of platelet aggregation and promotion of anti-inflammatory effects. Studies have shown that at a lower dose, resveratrol acts as an anti-apoptotic agent, providing cardioprotection as evidenced by increased expression in cell survival proteins, improved post-ischemic ventricular recovery and reduction of myocardial infarct size and cardiomyocyte apoptosis and maintains a stable redox environment compared to control. (109)

In 1997, Jang and colleagues published a seminal paper reporting the ability of resveratrol to inhibit carcinogenesis at multiple stages. Their finding that topical application of resveratrol reduced the number of skin tumours per mouse by up to $98 \%$ triggered research on resveratrol around the world.(98) Systemic administration of resveratrol has since been shown to inhibit the initiation and growth of tumours in a wide variety of rodent cancer models.(99) Jang and colleagues originally proposed that resveratrol might be an effective chemo-preventive agent because it inhibits the enzymatic activity of both forms of cyclooxygenase (COX). (98)

The in vitro studies indicate that transcriptional inhibition of COX2, as well as another important player in carcinogenesis, ornithine decarboxylase (ODC) could be accomplished through inhibition of protein kinase $\mathrm{C}$ (PKC). $(110,111)$ Resveratrol does not directly inhibit ODC activity (112), but reduces its expression in vivo and prevents its induction by carcinogens (113-115).

Angiogenesis is required to support the growth of most solid tumours beyond a diameter of $2-3 \mathrm{~mm}$. When delivered systemically at a dose of $2.5-100 \mathrm{mg}$ per $\mathrm{kg}$ (body weight), resveratrol inhibits tumour-induced neovascularization. $(116,117)$ Resveratrol modulates the expression and activity of multiple drug-metabolizing enzymes. In vitro, resveratrol inhibits the enzymatic activity of various cytochrome P450 (CYP) (118-121) and blocks their transcription through antagonism of the aryl hydrocarbon receptor (AHR) $(122,123)$, suggesting that resveratrol could cause a reduction in the exposure of cells to carcinogens. Another mechanism by which resveratrol could combat tumour formation is induction of cell cycle arrest and apoptosis. The anti-proliferative and pro-apoptotic effects of resveratrol in tumour cell lines have been extensively documented in vitro (124) and are supported by downregulation of cell cycle proteins (125-127) and increases in apoptosis (128-130) in tumour models in vivo.

ROS have been shown to have a role in the initiation and progression of cancer through directly damaging DNA and other macromolecules.(131,132) In addition to its possible modulation of antioxidant enzymes involved in the Phase II response, resveratrol has an intrinsic antioxidant capacity that could be related to its chemopreventive effects.

In addition to its anticancer activity, resveratrol has displayed beneficial activity against inflammatory responses via inhibition of COX1 and COX2 expression. (133) Resveratrol was reported to reduce the production of prostaglandin E2 (PGE2) and the formation of ROS in lipopolysaccharide (LPS)-activated microglial cells. $(134,135)$ Moreover, resveratrol was reported to suppress the activity of T- and B-cells, and macrophages.(136) Singh, et al., showed that resveratrol induced both caspasedependent and caspase-independent apoptosis in activated T-cells in experimental allergic encephalomyelitis- induced mice.(137) One study showed that resveratrol possesses analgesic property by inhibition of COX1 and COX 2.(138)

Resveratrol also possesses neuroprotective properties. It has been reported that resveratrol could protect against 
Huntington's disease (139), Alzheimer's disease (140) and Parkinson's disease (141).

In rodent models of diet-induced obesity, a high dose of resveratrol $(400 \mathrm{mg} / \mathrm{kg} / \mathrm{d})$ improves insulin sensitivity and lowers body weight (102), which has increased the interest and the speculation about its potential use as an anti-diabetic agent in humans. Nevertheless, recent work has shown that a one-year intervention with resveratrol at a dose of $200 \mathrm{mg} / \mathrm{kg} / \mathrm{d}$ seems to cause an increase in basal metabolic rate and total daily energy expenditure in the nonhuman primate Microcebus murinus $(142,143)$; indicating that resveratrol might have the potency to enhance energy expenditure thereby promoting weight loss.

Increased adventitial vasculogenesis is one of the pathological features of abdominal aortic aneurysm (AAA), and is thought to play an important role in the development of AAA, possibly through creating a conduit for inflammatory cell transport and establishing chronic inflammation in the aortic wall.(144) Resveratrol treatment resulted in downregulation of vascular endothelial growth factor (VEGF) A, a potent angiogenic and vascular permeability factor, and decreased neoangiogenesis in the aortic wall. The decreased neoangiogenesis by resveratrol treatment was associated with attenuation of macrophage infiltration and proinflammatory cytokines expression. Norata, et al. reported that resveratrol treatment reduced the expression of inflammatory markers and atherosclerotic plaque formation in apolipoprotein (Apo) E knockout mice.(145) Therefore, anti-angiogenic and anti-inflammatory effects of resveratrol may contribute to the prevention of AAA development. (146)

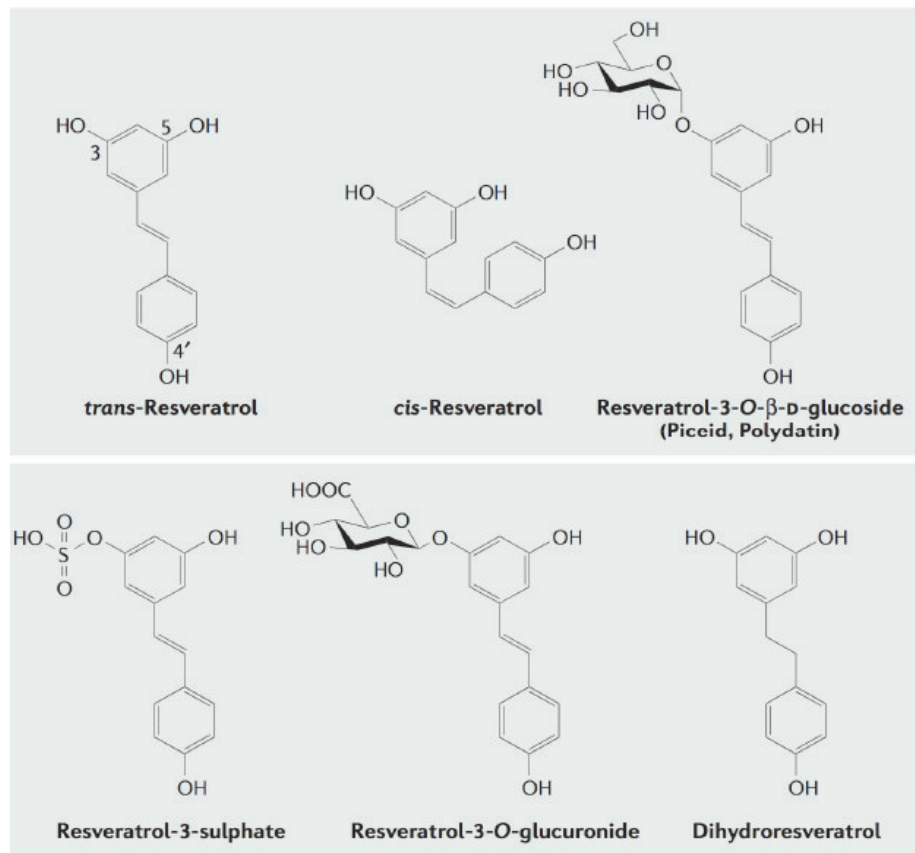

Published clinical trials have largely focused on characterizing the pharmacokinetics and metabolism of resveratrol. Recent studies have also evaluated safety and potential mechanisms of activity following multiple dosing, and have found resveratrol to be safe and reasonably welltolerated at doses of up to $5 \mathrm{~g}$ /day.(147) Though limited data is available on resveratrol's efficacy in chronic metabolic diseases in humans, the clinical trials that are available show much promise that resveratrol might be applied to improve general health status and prevent chronic disease in humans.

\section{Resveratrol: SIRT Activators}

Regardless of the established benefits of a CR diet, the severity of this dietary regime has limited adoption of this approach to increasing longevity, because few people can keep to such an unappealing lifestyle. It would therefore be desirable to provide an alternative route to obtaining the benefits of CR that would avoid the need for dietary regulation and that would be amenable to widespread use. The beneficial impact of increased SIRT1 activity observed in several animal models of disease has recently been observed in humans as well, where reduced SIRT1 expression in insulin-sensitive tissues was associated with reduced energy expenditure.(148)

Reversible acetylation is a key post-translational modification of target proteins. SIRT deacetylases represent the homolog of the yeast Sir2. Although seven SIRT have been found in mammals, all SIRT activators described to

Figure 2. Trans-resveratrol and related structures. Piceid is found in grapes and other natural sources of resveratrol. Resveratrol-3-sulphate, resveratrol-3-O-glucuronide and dihydroresveratrol are metabolites of resveratrol.(99) (Adapted with permission from Nature Publishing Group). 
Table 1. Dietary Sources of Resveratrol.(99) ND: not determined. (Adapted with permission from Nature Publishing Group).

\begin{tabular}{|c|c|c|}
\hline Source & $\begin{array}{l}\text { trans-Resveratrol } \\
\text { concentration }\end{array}$ & Comments \\
\hline \multicolumn{3}{|l|}{ Dietary } \\
\hline Red wines & $0.1-14.3 \mathrm{mgl}^{-1}$ & $\begin{array}{l}\text { cis-Resveratrol, trans-piceid and cis-piceid also present, typically at } \\
\text { slightly lower concentrations }\end{array}$ \\
\hline White wines & $<0.1-2.1 \mathrm{mg} \mathrm{l}^{-1}$ & $\begin{array}{l}\text { Generally resveratrol found at concentrations of }<0.1 \mathrm{mg} \mathrm{l}^{-1} \text {, exceptions } \\
\text { include Swiss, Portuguese and German Riesling wines, cis-resveratrol, } \\
\text { trans-piceid and cis-piceid also present }\end{array}$ \\
\hline Ports and sherries & Generally $<0.1 \mathrm{mgl}^{-1}$ & \\
\hline Grapes* & $0.16-3.54 \mu \mathrm{g} \mathrm{g}^{-1}$ & $\begin{array}{l}\text { Contents are similar for wine or table grapes, and black or white grapes. } \\
\text { trans-Piceid is predominant at concentrations of } 1.5-7.3 \mu \mathrm{g} \mathrm{g}^{-1}\end{array}$ \\
\hline Dry grape skins & $24.06 \mu \mathrm{g} \mathrm{g}^{-1}$ (average) & $\begin{array}{l}\text { trans-Piceid and cis-piceid found at concentrations of } 42.19 \mu \mathrm{g} \mathrm{g}^{-1} \text { and } \\
92.33 \mu \mathrm{g} \mathrm{g}^{-1} \text {, respectively }\end{array}$ \\
\hline Red grape juices & $0.50 \mathrm{mgl}^{-1}$ (average) & $\begin{array}{l}\text { trans-Piceid, cis-piceid and cis-resveratrol found at concentrations of } \\
3.38 \mathrm{mg} \mathrm{l}^{-1}, 0.79 \mathrm{mg} \mathrm{l}^{-1} \text { and } 0.06 \mathrm{mg} \mathrm{l}^{-1} \text {, respectively }\end{array}$ \\
\hline White grape juices & $0.05 \mathrm{mgl}^{-1}$ (average) & $\begin{array}{l}\text { trans-Piceid and cis-piceid found at concentrations of } 0.18 \mathrm{mgl}^{-1} \text { and } \\
0.26 \mathrm{mgl}^{-1} \text {, respectively }\end{array}$ \\
\hline Cranberry raw juice & $\sim 0.2 \mathrm{mgl}^{-1}$ & cis-Resveratrol also found at a concentration of $\sim 0.03 \mathrm{mgl}^{-1}$ \\
\hline Blueberries & Up to $\sim 32 \mathrm{ng} \mathrm{g}^{-1}$ & \\
\hline Bilberries & Up to $\sim 16 \mathrm{ng} \mathrm{g}^{-1}$ & \\
\hline Other Vaccinium berries & $\begin{array}{l}7-5,900 \mathrm{ng} \mathrm{g}^{-1} \\
\text { (drysample) }\end{array}$ & Highest concentrations in lingonberries \\
\hline Peanuts & $0.02-1.92 \mu \mathrm{gg}^{-1}$ & \\
\hline Roasted peanuts & $0.055 \mu \mathrm{gg}^{-1}$ & \\
\hline Boiled peanuts & $5.1 \mu \mathrm{gg}^{-1}$ & \\
\hline Peanut butters & $0.3-0.4 \mu \mathrm{g} \mathrm{g}^{-1}$ (average) & trans-Piceid also found at a concentration of $0.13 \mu \mathrm{gg}^{-1}$ \\
\hline $\begin{array}{l}100 \% \text { Natural peanut } \\
\text { butters }\end{array}$ & 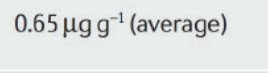 & trans-Piceid also found at a concentration of $0.14 \mu \mathrm{gg}^{-1}$ \\
\hline Pistachios & $0.09-1.67 \mu \mathrm{g} \mathrm{g}^{-1}$ & \\
\hline $\begin{array}{l}\text { Groundnuts (Arachis } \\
\text { hypogaea) }\end{array}$ & ND & \\
\hline Rhubarb & ND & \\
\hline Hops & $0.5-1 \mu \mathrm{g} \mathrm{g}^{-1}$ & $\begin{array}{l}\text { trans-Piceid and cis-piceid found at concentrations of } 2-9 \mu \mathrm{g} \mathrm{g}^{-1} \text { and } \\
0.9-6 \mu \mathrm{g} \mathrm{g}^{-1} \text {, respectively }\end{array}$ \\
\hline $\begin{array}{l}\text { Itadori (Polygonum } \\
\text { cuspidatum) tea }\end{array}$ & $0.68 \mathrm{mgl}^{-1}$ & trans-Piceid also found at a concentration of $9.1 \mathrm{mgl}^{-1}$ \\
\hline \multicolumn{3}{|l|}{ Herbal } \\
\hline Veratrum (Lily) & ND & \\
\hline Cassia quinquangulata & ND & \\
\hline Gnetum klossii & ND & \\
\hline Polygonum cuspidatum & $0.524 \mathrm{mg} \mathrm{g}^{-1}$ & trans-Piceid also found at a concentration of $1.65 \mathrm{mg} \mathrm{g}^{-1}$ \\
\hline $\begin{array}{l}\text { Rhubarb (Rheum } \\
\text { rhaponticum) dry root }\end{array}$ & $3.9 \mathrm{mg} \mathrm{g}^{-1}$ & \\
\hline Yucca schidigera bark & ND & \\
\hline
\end{tabular}

date act through SIRT1.(73) SIRT1 activators, with a focus on therapeutic applications, primarily related to the use of pharmaceuticals and nutraceuticals containing resveratrol, and the development of second-generation activators unrelated to resveratrol.(73)

Resveratrol offers protection in models of stress- and age-associated diseases, including chronic overfeeding, insulin resistance, type 2 diabetes, and cardiovascular dysfunction.(101,102) The mechanisms behind these effects may rely on the fact that resveratrol mimics some of the metabolic actions of $\mathrm{CR}$, as a series of studies on humans have suggested.(107) Resveratrol interacts with many stress-related targets in the cell, including the mammalian $\mathrm{NAD}^{+}$-dependent deacetylase SIRT1 $(99,102)$, although the resveratrol-SIRT1 interaction may be indirect (149). SIRT1 is a member of a family of proteins (SIRT) that have been linked to longevity in yeast, flies, and worms. $(9,85,150)$

A number of subsequent studies showed that resveratrol induced SIRT1 activity in several species. (151) Furthermore, resveratrol mimics numerous aspects 
of calorie restriction in all eukaryotes tested to date $(8,101$ $103,106,152,153)$ and in most of them, the effect appears dependent on SIRT1 $(8,102,103)$.

Resveratrol was also shown to increase energy expenditure in mice $(101,102)$, through increased SIRT1 activation, and during conditions of high fat availability, resveratrol was capable of preventing diet-induced obesity and the onset of obesity-related metabolic diseases, so ultimately protecting mice against the lifespan curbing effects associated with high calorie intake. The molecular mechanism underlying these beneficial effects seem to depend on the resveratrol-induced increase in mitochondrial content, which is explained by increased signaling through the SIRT1/ PGC1 $\alpha$ axis.(102) More recently, some studies have questioned the direct activation of SIRT1 by resveratrol.(154,155)

Several reports demonstrate that resveratrol can also activate AMPK (101,156-158), which reconciles with the positive effect on the mitochondrial respiratory chain that has been reported (159). Hawley, et al., reported that resveratrol-induced AMPK activation in isogenic cell lines, stably expressing AMPK complexes containing AMPinsensitive $\gamma 2$ subunit variants (R531G), derives from an AMP/ATP imbalance as a consequence of interference with mitochondrial respiration.(160) Although the idea was put forward that the resveratrol-induced AMPK activation was dependent on SIRT1 (161), the use of mouse embryonic fibroblast cells from SIRT1 knock-out mice unequivocally demonstrated that SIRT1 is dispensable for resveratrolinduced AMPK activation $(156,162)$. On the contrary, resveratrol cannot activate SIRT1 in the absence of functional AMPK.(162,163) So, the current working mechanism of resveratrol that evolved from all these reports is that SIRT1 functions as the downstream mediator of AMPK, instead of being a direct molecular target of resveratrol. Canto, et al. (164) have shown in that respect that the AMPK induced increase in $\mathrm{NAD}^{+}$levels, as a consequence of increased fatty

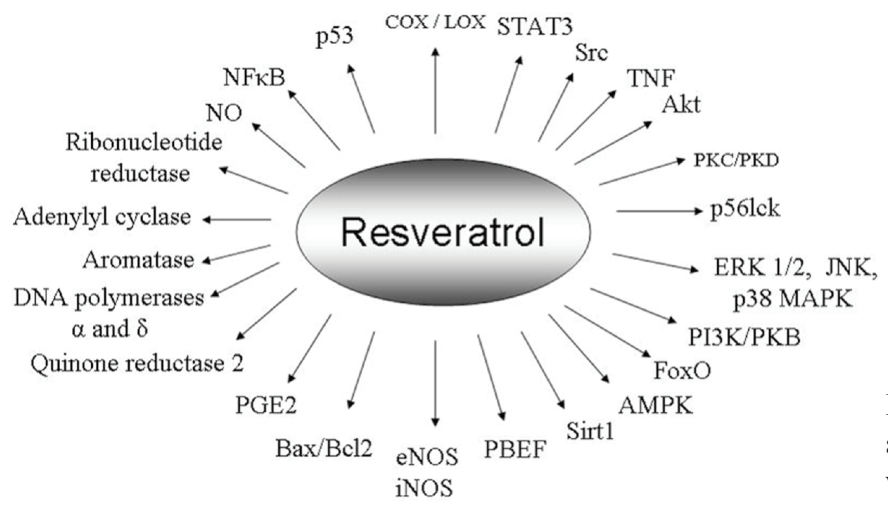

Figure 3. MolecularTargets of Resveratrol: as a pharmacological agent, resveratrol has wide spectrum of targets.(109) (Adapted with permission from University of Massachussets). acid oxidation, leads to SIRT1 activation.

Diminished mitochondrial oxidative phosphorylation and aerobic capacity are associated with reduced longevity. Resveratrol's effects were associated with an induction of genes for oxidative phosphorylation and mitochondrial biogenesis and were largely explained by an resveratrolmediated decrease in PGC- $1 \alpha$ acetylation and an increase in PGC- $1 \alpha$ activity. This mechanism is consistent with resveratrol being a known activator of the protein deacetylase, SIRT1, and by the lack of effect of resveratrol in SIRT1-/- mouse embryonic fibroblast (MEF). Importantly, resveratrol treatment protected mice against diet-inducedobesity and insulin resistance.(102)

The mechanisms by which enhanced autophagy can improve organismal health and longevity are largely elusive. As a possibility, increased autophagy might improve cellular resistance to stress by augmenting the metabolic buffering capacity of cells. Alternatively, autophagy might enhance organellar turnover and mediate a 'cleaning effect', thereby preventing the accumulation of damaged/old (and hence potentially harmful) mitochondria and lysosomes. Irrespective of these considerations, data establish the cardinal role of SIRT-1-elicited autophagy in mediating the anti-aging effects of $\mathrm{CR}$ and resveratrol.(10)

SIRT1 activation restores bone marrow-derived early outgrowth cell (EOC) chemokine secretion and increases the in vitro and in vivo angiogenic activity of EOCs in diabetic animals. These findings suggest a pivotal role for SIRT1 in diabetes-induced EOC dysfunction and that its pharmacologic activation may provide a new strategy for the restoration of EOC-mediated repair mechanisms.(165) In fact, resveratrol treatment has been demonstrated to rescue adult stem cell decline, slow down bodyweight loss, improve trabecular bone structure and mineral density, and significantly extend the lifespan in zinc metallopeptidase STE24 (Zmp-ste24) $)^{-/-}$mice, which are deficient for Zmpste24, a metalloproteinase responsible for prelamin A 
maturation.(166)

Over the past several years, chemically distinct molecules mimicking resveratrol effects were developed to activate SIRT at much lower doses.(167-169) Sirtris Pharmaceuticals identified and characterized some small molecules designed to activate SIRT1 that are structurally unrelated to resveratrol. One of them, named SRT1720, was 1000 -fold more potent than resveratrol. Another strategy for SIRT activation is the use of agents that increase $\mathrm{NAD}^{+}$ concentrations and, consequently, potentiate mammalian SIRT functions. For example, increased intracellular $\mathrm{NAD}^{+}$ concentration has been shown to activate SIRT1 in brain, and has been proposed to help explain the protective effects of CR in a mouse model of Alzheimer's disease.(170) Sauve and collaborators developed NR and derivatives that potently stimulate $\mathrm{NAD}^{+}$biosynthesis in mammalian cells and thus, could provide an effective pharmacological means to increase SIRT activities.(171) Resveratrol is the best studied natural compound that is able to activate SIRT1. Synthetic drugs mimicking resveratrol and activating SIRT at much lower doses than resveratrol have been developed over the past several years.(73)

\section{Conclusion}

The natural polyphenolic compound resveratrol has received interest as several findings implicated resveratrol as a potent SIRT1 activator capable of mimicking the effects of calorie restriction, and regulating longevity in lower organisms. Given the worldwide increase in age-related metabolic diseases the beneficial effects of resveratrol on metabolism and healthy aging in humans are currently a topic of intense investigation.

\section{References}

1. Della-Morte D, Ricordi C, Rundek T. The fountain of youth: role of sirtuins in aging and regenerative medicine. Regen Med. 2013; 8: 681-3.

2. Willcox BJ, Willcox DC. Caloric restriction, caloric restriction mimetics, and healthy aging in Okinawa: controversies and clinical implications. Curr Opin Clin Nutr Metab Care. 2014; 17: 51-8.

3. Mizushima S, Moriguchi EH, Ishikawa P, Hekman P, Nara Y, Mimura $\mathrm{G}$, et al. Fish intake and cardiovascular risk among middle-aged Japanese in Japan and Brazil. J Cardiovasc Risk. 1997; 4: 191-9.

4. Fontana L, Partridge L, Longo VD. Extending healthy life span from yeast to humans. Science. 2010; 328: 321-6.

5. De Cabo R, Carmona-Gutierrez D, Bernier, Hall MN, Madeo F. The search for antiaging interventions: from elixirs to fasting regimens. Cell. 2014; 157: 1515-26.

6. Dali-Youcef N, Lagouge M, Froelich S, Koehl C, Schoonjans K, Auwerx J. Sirtuins: the 'magnificent seven', function, metabolism and longevity. Ann Med. 2007; 39: 335-45.

7. Corbi G, Conti V, Scapagnini G, Filippelli A, Ferrara N. Role of sirtuins, calorie restriction and physical activity in aging. Front Biosci (Elite Ed). 2012; 4: 768-78.

8. Howitz KT, Bitterman KJ, Cohen HY, Lamming DW, Lavu S, Wood JG, et al. Small molecule activators of sirtuins extend Saccharomyces cerevisiae lifespan. Nature. 2003; 425: 191-6.

9. Haigis MC, Guarente LP. Mammalian sirtuins emerging roles in physiology, aging, and calorie restriction. Genes Dev. 2006; 20: 2913-21.

10. Morselli E, Maiuri MC, Markaki M, Megalou E, Pasparaki A, Palikaras K, et al. Caloric restriction and resveratrol promote longevity through the Sirtuin-1-dependent induction of autophagy. Cell Death Dis. 2010; 1: e10. doi: 10.1038/cddis.2009.8.

11. Rando TA. Stem cells, ageing and the quest for immortality. Nature. 2006; 441: 1080-6.

12. Rossi DJ, Jamieson CH, Weissman IL. Stems cells and the pathways

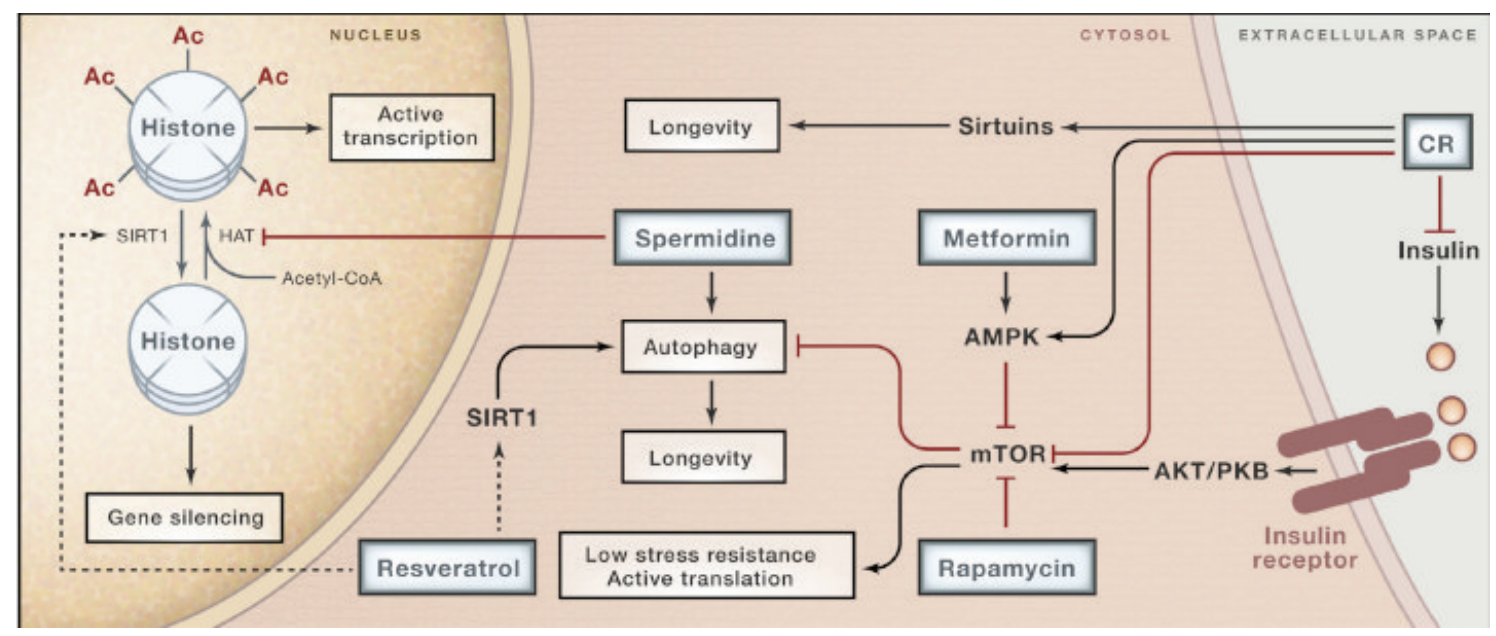

Figure 4. Molecular Targets for CR and Pharmacological Interventions against Premature Aging.(5) (Adapted with permission from Elsevier). 
to aging and cancer. Cell. 2008; 132: 681-96.

13. Sahin E, Depinho RA. Linking functional decline of telomeres, mitochondria and stem cells during ageing. Nature. 2010; 464: 5208.

14. Janzen V, Forkert R, Fleming HE, Saito Y, Waring MT, Dombkowski $\mathrm{DM}$, et al. Stem-cell ageing modified by the cyclin-dependent kinase inhibitor p16INK4a. Nature. 2006. 443: 421-6.

15. Balaban RS, Nemoto S, Finkel T. Mitochondria, oxidants, and aging. Cell. 2005; 120: 483-95.

16. Ito K, Hirao A, Arai F, Takubo K, Matsuoka S, Miyamoto K, et al. Reactive oxygen species act through p38 MAPK to limit the lifespan of hematopoietic stem cells. Nat Med. 2006; 12: 446-51.

17. Ito K, Hirao A, Arai F, Matsuoka S, Takubo K, Hamaguchi I, et al. Regulation of oxidative stress by ATM is required for self-renewal of haematopoietic stem cells. Nature. 2004; 431: 997-1002.

18. Miyamoto K, Araki KY, Naka K, Arai F, Takubo K, Yamazaki S, et al. Foxo3a is essential for maintenance of the hematopoietic stem cell pool. Cell Stem Cell. 2007; 1: 101-12.

19. Paik JH, Ding Z, Narurkar R, Ramkissoon S, Muller F, Kamoun WS, et al. FoxOs cooperatively regulate diverse pathways governing neural stem cell homeostasis. Cell Stem Cell. 2009; 5: 540-53.

20. Renault VM, Rafalski VA, Morgan AA, Salih DA, Brett JO, Webb $\mathrm{AE}$, et al. FoxO3 regulates neural stem cell homeostasis. Cell Stem Cell. 2009; 5: 527-39.

21. Tothova Z, Kollipara R, Huntly BJ, Lee BH, Castrillon DH, Cullen $\mathrm{DE}$, et al. FoxOs are critical mediators of hematopoietic stem cell resistance to physiologic oxidative stress. Cell. 2007; 128: 325-39.

22. Brown K, Xie S, Qiu X, Mohrin M, Shin J, Liu Y, et al. SIRT3 reverses aging-associated degeneration. Cell Rep. 2013; 3: 319-27.

23. Mercken EM, Carboneau BA, Krzysik-Walker SM, de Cabo R. Of mice and men: the benefits of caloric restriction, exercise, and mimetics. Ageing Res Rev. 2012; 11: 390-8.

24. Wing RR, Phelan S. Long-term weight loss maintenance. Am J Clin Nutr. 2005; 82 (Suppl 1): S222-5.

25. Gurwitz JH, Goldberg RJ, Gore JM. Coronary thrombolysis for the elderly? JAMA. 1991; 265: 1720-3.

26. Ungvari Z, Kaley G, de Cabo R, Sonntag WE, Csiszar A. Mechanisms of vascular aging: new perspectives. J Gerontol A Biol Sci Med Sci. 2010; 65: 1028-41.

27. Ungvari Z, Bailey-Downs L, Gautam T, Sosnowska D, Wang M, Monticone RE, et al. Age-associated vascular oxidative stress, Nrf2 dysfunction, and NF- $\{$ kappa $\} \mathrm{B}$ activation in the nonhuman primate Macaca mulatta. J Gerontol A Biol Sci Med. 2011; 66: 866-75.

28. Lakatta EG, Wang M, Najjar S. Arterial aging and subclinical arterial disease are fundamentally intertwined at macroscopic and molecular levels. Med Clin North Am. 2009; 93: 583-604.

29. Lloyd-Jones D, Adams RJ, Brown TM, Carnethon M, Dai S, De Simone G, et al. Heart disease and stroke statistics-2010 update: a report from the American Heart Association. Circulation. 2010; 12: e46-e215. doi: 10.1161/CIRCULATIONAHA.109.192667.

30. Lakatta EG. The reality of aging viewed from the arterial wall. Artery Res. 2013; 7: 73-80.

31. Wang M, Monticone RE, Lakatta EG. Arterial aging: a journey into subclinical arterial disease. Curr Opin Nephrol Hypertens. 2010; 19: 201-7.

32. Wang M, Lakatta EG. Central arterial aging: humans to molecules. In: Safar M, editor. Handbook of Hypertension: Arterial Stiffness in Hypertension. Amsterdam: Elsevier; 2006. p.137-160.

33. Wang M, Khazan B, Lakatta EG. Central arterial aging and angiotensin II signaling. Curr Hypertens Rev. 2010; 6: 266-81.

34. Wang M, Jiang L, Monticone RE, Lakatta EG. Proinflammation: the key to arterial aging. Trends Endocrinol Metab. 2014; 25: 72-9.
35. World Health Organization. Joint WHO/FAO expert consultation on diet, nutrition and the prevention of the chronic diseases. Geneva: World Health Organization; 2003.

36. World Health Organization. Preventing chronic diseases: a vital investment: WHO global report. Geneva: WHO Press; 2005.

37. Department of Health and Human Services, National Center for Chronic Disease Prevention and Health Promotion. Chronic disease, the public health challenge of the 21 st century. Atlanta: Centers for Disease Control and Prevention; 2009.

38. Willcox BJ, Willcox DC, Todoriki H, Fujiyoshi A, Yano K, He Q, et al. Caloric restriction, the traditional Okinawan diet, and healthy aging: the diet of the world's longest-lived people and its potential impact on morbidity and life span. Ann NY Acad Sci. 2007; 1114: 434-55.

39. Willcox DC, Willcox BJ, Todoriki H, Suzuki M. The Okinawan diet: health implications of a low-calorie, nutrient-dense, antioxidantrich dietary pattern low in glycemic load. J Am Coll Nutr. 2009; 28 (Suppl): S500-16.

40. Willcox DC, Willcox BJ, Yasura S, Ashitomi I, Suzuki M. Gender gap in healthspan and life expectancy in Okinawa: health behaviours. Asian J Gerontol Geriatr. 2012; 7: 49-58.

41. Gavrilova NS, Gavrilov LA. Comments on dietary restriction, Okinawa diet and longevity. Gerontology. 2012; 58: 221-3.

42. Willcox DC, Willcox BJ, Todoriki H, Curb JD, Suzuki M. Caloric restriction and human longevity: what can we learn from the Okinawans? Biogerontology. 2006; 7: 173-7.

43. Colman RJ, Anderson RM, Johnson SC, Kastman EK, Kosmatka KJ, Beasley TM, et al. Caloric restriction delays disease onset and mortality in rhesus monkeys. Science. 2009; 325: 201-4.

44. Mattison JA, Roth GS, Beasley TM, Tilmont EM, Handy AM, Herbert $\mathrm{RL}$, et al. Impact of caloric restriction on health and survival in rhesus monkeys from the NIA study. Nature. 2012; 489: 318-21.

45. Weindruch R, Walford RL, Fligiel S, Guthrie D. The retardation of aging in mice by dietary restriction: longevity, cancer, immunity and lifetime energy intake. J Nutr. 1986; 116: 641-54.

46. Koubova J, Guarente L. How does calorie restriction work? Genes Dev. 2003; 17: 313-21.

47. Anderson RM, Weindruch R. The caloric restriction paradigm: implications for healthy human aging. Am J Hum Biol. 2012; 24: 101-6.

48. Sohal RS, Weindruch R. Oxidative stress, caloric restriction, and aging. Science. 1996; 273: 59-63.

49. Mercken EM, Crosby SD, Lamming DW, JeBailey L, KrzysikWalker S, Villareal DT, et al. Calorie restriction in humans inhibits the PI3K/AKT pathway and induces a younger transcription profile. Aging Cell. 2013; 12: 645-51.

50. Wallace DC. A mitochondrial paradigm of metabolic and degenerative diseases, aging, and cancer: a dawn for evolutionary medicine. Annu Rev Genet. 2005; 39: 359-407.

51. Hebert AS, Dittenhafer-Reed KE, Yu W, Bailey DJ, Selen ES, Boersma MD, et al. Calorie Restriction and SIRT3 Trigger Global Reprogramming of the Mitochondrial Protein Acetylome. Mol Cell. 2013; 49: 186-99.

52. Longo VD, Mattson MP. Fasting: molecular mechanism and clinical application. Cell Metab. 2014; 19: 181-92.

53. Davinelli S, Willcox DC, Scapagnini G. Extending healthy ageing: nutrient sensitive pathway and centenarian population. Immun Ageing. 2012; 9: 9. doi: 10.1186/1742-4933-9-9.

54. Murakami A, Ishida H, Kubo K, Furukawa I, Ikeda Y, Yonaha M, et al. Suppressive effects of Okinawan food items on free radical generation from stimulated leukocytes and identification of some active constituents: implications for the prevention of inflammation- 
associated carcinogenesis. Asian Pacific J Cancer Prev. 2005; 6: 437-48.

55. Huffman DM. Exercise as a calorie restriction mimetic: implications for improving healthy aging and longevity. Interdiscip Top Gerontol. 2010; 37: 157-74.

56. Warburton DE, Nicol CW, Bredin SS. Health benefits of physical activity: the evidence. CMAJ. 2006; 174: 801-9.

57. Fontana L, Meyer TE, Klein S, Holloszy JO. Long-term low-calorie low-protein vegan diet and endurance exercise are associated with low cardiometabolic risk. Rejuvenation Res. 2007; 10: 225-34.

58. Lee IM, Skerrett PJ. Physical activity and all-cause mortality: what is the dose-response relation? Med Sci Sports Exerc. 2001; 33 (Suppl 6): S459-71; discussion S493-4.

59. Huffman DM, Moellering DR, Grizzle WE, Stockard CR, Johnson MS, Nagy TR. Effect of exercise and calorie restriction on biomarkers of aging in mice. Am J Physiol Regul Integr Comp Physiol. 2008; 294: R1618-27.

60. Nicklas BJ, Wang X, You T, Lyles MF, Demons J, Easter L, et al. Effect of exercise intensity on abdominal fat loss during calorie restriction in overweight and obese postmenopausal women: a randomized, controlled trial. Am J Clin Nutr. 2009; 89: 1043-52.

61. Haigis MC, Sinclair DA. Mammalian sirtuins: biological insights and disease relevance. Annu Rev Pathol. 2010; 5: 253-95.

62. Feldman JL, Dittenhafer-Reed KE, Denu JM. Sirtuin catalysis and regulation. J Biol Chem. 2012; 287: 42419-27.

63. Vaziri H, Dessain SK, Ng Eaton E, Imai SI, Frye RA, Pandita TK, et al. hSIR2(SIRT1) functions as an NAD-dependent p53 deacetylase. Cell. 2001; 107: 149-59.

64. Brunet A, Sweeney LB, Sturgill JF, Chua KF, Greer PL, Lin Y, et al. Stress-dependent regulation of FOXO transcription factors by the SIRT1 deacetylase. Science. 2004; 303: 2011-5.

65. Rodgers JT, Lerin C, Haas W, Gygi SP, Spiegelman BM, Puigserver P. Nutrient control of glucose homeostasis through a complex of PGC-1alpha and SIRT1. Nature. 2005; 434: 113-8.

66. Yeung F, Hoberg JE, Ramsey CS, Keller MD, Jones DR, Frye RA, et al. Modulation of NF-kappaB-dependent transcription and cell survival by the SIRT1 deacetylase. EMBO J. 2004; 23: 2369-80.

67. Silva JP, Wahlestedt C. Role of Sirtuin 1 in metabolic regulation. Drug Discov Today. 2010; 15: 781-91.

68. Cantó C, Jiang LQ, Deshmukh AS, Mataki C, Coste A, Lagouge M, et al. Interdependence of AMPK and SIRT1 for metabolic adaptation to fasting and exercise in skeletal muscle. Cell Metab. 2010; 11: 213-9.

69. Hallows WC, Yu W, Denu JM. Regulation of glycolytic enzyme phosphoglycerate mutase-1 by Sirt1 protein-mediated deacetylation. J Biol Chem. 2012; 287: 3850-8.

70. Iwabu M, Yamauchi T, Okada-Iwabu M, Sato K, Nakagawa T, Funata M, et al. Adiponectin and AdipoR1 regulate PGC-1alpha and mitochondria by $\mathrm{Ca}(2+)$ and AMPK/SIRT1. Nature. 2010; 464: 1313-9.

71. Purushotham A, Xu Q, Li X. Systemic SIRT1 insufficiency results in disruption of energy homeostasis and steroid hormone metabolism upon high-fat-diet feeding. FASEB J. 2012; 26: 656-67.

72. Wang RH, Kim HS, Xiao C, Xu X, Gavrilova O, Deng CX. Hepatic Sirt1 deficiency in mice impairs mTorc2/Akt signaling and results in hyperglycemia, oxidative damage, and insulin resistance. J Clin Invest. 2011; 121: 4477-90.

73. Villalba JM, de Cabo R, Alcain FJ. A patent review of sirtuin activators: an update. Expert Opin Ther Patents. 2012; 22: 355-67.

74. Kenyon CJ. The genetics of ageing. Nature. 2010; 464: 504-12.

75. Zoncu R, Efeyan A, Sabatini DM. mTOR: from growth signal integration to cancer, diabetes and ageing. Nat Rev Mol Cell Biol.
2011; 12: 21-35.

76. Demontis F, Perrimon N. FOXO/4E-BP signaling in Drosophila muscles regulates organism-wide proteostasis during aging. Cell. 2010; 143: 813-25.

77. Durieux J, Wolff S, Dillin A. The cell-non-autonomous nature of electron transport chain-mediated longevity. Cell. 2011; 144: 79-91.

78. Guarente L. Mitochondria - a nexus for aging, calorie restriction, and sirtuins? Cell. 2008; 132: 171-6.

79. Haigis MC, Sinclair DA. Mammalian sirtuins: biological insights and disease relevance. Annu Rev Pathol. 2010; 5: 253-95.

80. Houtkooper RH, Canto C, Wanders RJ, Auwerx J. The secret life of NAD+: an old metabolite controlling new metabolic signaling pathways. Endocr Rev. 2010; 31: 194-223.

81. Chalkiadaki A, Guarente L. Sirtuins mediate mammalian metabolic responses to nutrient availability. Nat Rev Endocrinol. 2012; 8: 28796.

82. Houtkooper RH, Auwerx J. Exploring the therapeutic space around NAD+. J Cell Biol. 2012; 199: 205-9.

83. Yoshino J, Mills KF, Yoon MJ, Imai S. Nicotinamide mononucleotide, a key $\mathrm{NAD}(+)$ intermediate, treats the pathophysiology of diet- and age-induced diabetes in mice. Cell Metab. 2011; 14: 528-36.

84. Canto C, Auwerx J. Targeting sirtuin 1 to improve metabolism: all you need is NAD(+)? Pharmacol Rev. 2012; 64: 166-87.

85. Mouchiroud L, Houtkooper RH, Moullen N, Katsyuba E, Ryu D, Canto C, et al. The NAD+/Sirtuin Pathway Modulates Longevity through Activation of Mitochondrial UPR and FOXO Signaling. Cell. 2013; 154: 430-41.

86. Houtkooper RH, Williams RW, Auwerx J. Metabolic networks of longevity. Cell. 2010; 142: 9-14.

87. Lin SJ, Defossez PA, Guarente L. Requirement of NAD and SIR2 for life-span extension by calorie restriction in Saccharomyces cerevisiae. Science. 2000; 289: 2126-8.

88. Rogina B, Helfand SL. Sir2 mediates longevity in the fly through a pathway related to calorie restriction. Proc Natl Acad Sci USA. 2004; 101: 15998-6003.

89. Wang Y, Tissenbaum HA. Overlapping and distinct functions for a Caenorhabditis elegans SIR2 and DAF-16/FOXO. Mech Ageing Dev. 2006; 127: 48-56.

90. Lin SJ, Kaeberlein M, Andalis AA, Sturtz LA, Defossez PA, Culotta $\mathrm{VC}$, et al. Calorie restriction extends Saccharomyces cerevisiae lifespan by increasing respiration. Nature. 2002; 418: 344-8.

91. Lin SJ, Ford E, Haigis M, Liszt G, Guarente L. Calorie restriction extends yeast life span by lowering the level of NADH. Genes Dev. 2014; 18: 12-6.

92. Kaeberlein M, Kirkland KT, Fields S, Kennedy BK. Sir2-independent life span extension by calorie restriction in yeast. PLoS Biol. 2004; 2: E296.

93. Kaeberlein M, Hu D, Kerr EO, Tsuchiya M, Westman EA, Dang N, et al. Increased life span due to calorie restriction in respiratorydeficient yeast. PLoS Genet. 2005; 1: e69.

94. Takaoka MJ. Of the phenolic substances of white hellebore (Veratrum grandiflorum Loes. fil.). J Faculty Sci Hokkaido Imperial University. 1940; 3: 1-16.

95. Nonomura S, Kanagawa H, Makimoto A. [Chemical Constituents of Polygonaceous Plants. I. Studies on the Components of KO-JOKON. (Polygonum Cuspidatum Sieb. Et Zucc.)]. Yakugaku Zasshi. 1963; 83: 988-90.

96. Siemann EH, Creasy LL. Concentration of the phytoalexin resveratrol in wine. Am J Enol Vitic. 1992; 43: 49-52.

97. Liu BL, Zhang X, Zhang W, Zhen HN. New enlightenment of French Paradox: resveratrol's potential for cancer chemoprevention and anti-cancer therapy. Cancer Biol Ther. 2007; 6: 1833-6. 
98. Jang M, Cai L, Udeani GO, Slowing KV, Thomas CF, Beecher CW, et al. Cancer chemopreventive activity of resveratrol, a natural product derived from grapes. Science. 1997; 275: 218-20.

99. Baur JA, Sinclair DA. Therapeutic potential of resveratrol: the in vivo evidence. Nat Rev Drug Discov. 2006; 5: 493-506.

100. Vang O, Ahmad N, Baile CA, Baur JA, Brown K, Csiszar AD, et al. What is new for an old molecule? Systematic review and recommendations on the use of resveratrol. PLoS One. 2011; 6: e19881. doi: 10.1371/journal.pone.0019881.

101. Baur JA, Pearson KJ, Price NL, Jamieson HA, Lerin C, Kalra A, et al. Resveratrol improves health and survival of mice on a high-calorie diet. Nature. 2006; 444: 337-42.

102. Lagouge M, Argmann C, Gerhart-Hines Z, Meziane H, Lerin C, Daussin F, et al. Resveratrol improves mitochondrial function and protects against metabolic disease by activating SIRT1 and PGC1alpha. Cell. 2006; 127: 1109-22.

103. Wood JG, Rogina B, Lavu S, Howitz K, Helfand SL, Tatar M, et al. Sirtuin activators mimic caloric restriction and delay ageing in metazoans. Nature. 2004; 430: 686-9.

104. Agarwal B, Baur JA. Resveratrol and life extension. Ann NY Acad Sci. 2011; 1215: 138-43.

105. Bass TM, Weinkove D, Houthoofd K, Gems D, Partridge L. Effects of resveratrol on lifespan in Drosophila melanogaster and Caenorhabditis elegans. Mech Ageing Dev. 2007; 128: 546-52.

106. Valenzano DR, Terzibasi E, Genade T, Cattaneo A, Domenici L, Cellerino A. Resveratrol prolongs lifespan and retards the onset of age-related markers in a short-lived vertebrate. Curr Biol. 2006; 16: 296-300.

107. Timmers S, Auwerx J, Schrauwen P. The journey of resveratrol from yeast to human. Aging (Albany NY). 2012; 4: 146-58.

108. Halliwell B. Dietary polyphenols: good, bad, or indifferent for your health? Cardiovasc Res. 2007; 73: 341-7.

109. Mukherjee S, Dudley JI, Das DK. Dose-dependency of resveratrol in providing health benefits. Dose Response. 2010; 8: 478-500.

110. Subbaramaiah K, Chung WJ, Michaluart P, Telang N, Tanabe T, Inoue $\mathrm{H}$, et al. Resveratrol inhibits cyclooxygenase- 2 transcription and activity in phorbol ester-treated human mammary epithelial cells. J Biol Chem. 1998; 273: 21875-82.

111. Stewart JR, Ward NE, Ioannides CG, O'Brian CA. Resveratrol preferentially inhibits protein kinase $\mathrm{C}$-catalyzed phosphorylation of a cofactor-independent, arginine-rich protein substrate by a novel mechanism. Biochemistry. 1999; 38: 13244-51.

112. Schneider Y, Vincent F, Duranton B, Badolo L, Gossé F, Bergmann C, et al. Anti-proliferative effect of resveratrol, a natural component of grapes and wine, on human colonic cancer cells. Cancer Lett. 2000; 158: 85-91.

113. Khanduja KL, Bhardwaj A, Kaushik G. Resveratrol inhibits $\mathrm{N}$-nitrosodiethylamine-induced ornithine decarboxylase and cyclooxygenase in mice. J Nutr Sci Vitaminol (Tokyo). 2004; 50: 61-5.

114. Fu ZD, Cao Y, Wang KF, Xu SF, Han R. [Chemopreventive effect of resveratrol to cancer]. Ai Zheng. 2004; 23: 869-73.

115. Afaq F, Adhami VM, Ahmad N. Prevention of short-term ultraviolet $\mathrm{B}$ radiation-mediated damages by resveratrol in SKH-1 hairless mice. Toxicol Appl Pharmacol. 2003; 186: 28-37.

116. Kimura Y, Okuda H. Resveratrol isolated from Polygonum cuspidatum root prevents tumor growth and metastasis to lung and tumor-induced neovascularization in Lewis lung carcinoma-bearing mice. J Nutr. 2001; 131: 1844-9.

117. Tseng SH, Lin SM, Chen JC, Su YH, Huang HY, Chen CK, et al. Resveratrol suppresses the angiogenesis and tumor growth of gliomas in rats. Clin Cancer Res. 2004; 10: 2190-202.
118. Yu C, Shin YG, Kosmeder JW, Pezzuto JM, van Breemen RB. Liquid chromatography/tandem mass spectrometric determination of inhibition of human cytochrome P450 isozymes by resveratrol and resveratrol-3-sulfate. Rapid Commun Mass Spectrom. 2003; 17: 307-13.

119. Piver B, Berthou F, Dreano Y, Lucas D. Inhibition of CYP3A, CYP1A and CYP2E1 activities by resveratrol and other non volatile red wine components. Toxicol Lett. 2001; 125: 83-91.

120. Chang TK, Lee WB, Ko HH. Trans-resveratrol modulates the catalytic activity and mRNA expression of the procarcinogen-activating human cytochrome P450 1B1. Can J Physiol Pharmacol. 2000; 78: 874-81.

121. Chan WK, Delucchi AB. Resveratrol, a red wine constituent, is a mechanism-based inactivator of cytochrome P450 3A4. Life Sci. 2000; 67: 3103-12.

122. Ciolino HP, Daschner PJ, Yeh GC. Resveratrol inhibits transcription of CYP1A1 in vitro by preventing activation of the aryl hydrocarbon receptor. Cancer Res. 1998; 58: 5707-12.

123. Casper RF, Quesne M, Rogers IM, Shirota T, Jolivet A, Milgrom E, et al. Resveratrol has antagonist activity on the aryl hydrocarbon receptor: implications for prevention of dioxin toxicity. Mol Pharmacol. 1999; 56: 784-90.

124. Aggarwal BB, Bhardwaj A, Aggarwal RS, Seeram NP, Shishodia S, Takada Y. Role of resveratrol in prevention and therapy of cancer: preclinical and clinical studies. Anticancer Res. 2004; 24: 2783840.

125. Yu L, Sun ZJ, Wu SL, Pan CE. Effect of resveratrol on cell cycle proteins in murine transplantable liver cancer. World J Gastroenterol. 2003; 9: 2341-3.

126. Schneider Y, Duranton B, Gossé F, Schleiffer R, Seiler N, Raul F. Resveratrol inhibits intestinal tumorigenesis and modulates hostdefense-related gene expression in an animal model of human familial adenomatous polyposis. Nutr Cancer. 2001; 39: 102-7.

127. Reagan-Shaw S, Afaq F, Aziz MH, Ahmad N. Modulations of critical cell cycle regulatory events during chemoprevention of ultraviolet B-mediated responses by resveratrol in SKH-1 hairless mouse skin. Oncogene. 2004; 23: 5151-60.

128. Garvin S, Ollinger K, Dabrosin C. Resveratrol induces apoptosis and inhibits angiogenesis in human breast cancer xenografts in vivo. Cancer Lett. 2006; 231: 113-22.

129. Provinciali M, Re F, Donnini A, Orlando F, Bartozzi B, Di Stasio $\mathrm{G}$, et al. Effect of resveratrol on the development of spontaneous mammary tumors in HER-2/neu transgenic mice. Int J Cancer. 2005; $115: 36-45$.

130. Zhou HB, Chen JJ, Wang WX, Cai JT, Du Q. Anticancer activity of resveratrol on implanted human primary gastric carcinoma cells in nude mice. World J Gastroenterol. 2005; 11: 280-4.

131. Kensler T, Guyton K, Egner P, McCarthy T, Lesko S, Akman S. Role of reactive intermediates in tumor promotion and progression. Prog Clin Biol Res. 1995; 391: 103-16.

132. Gromadzinska J, Wasowicz W. The role of reactive oxygen species in the development of malignancies. Int J Occup Med Environ Health. 2000; 13: 233-5.

133. Kundu JK, Shin YK, Kim SH, Surh YJ. Resveratrol inhibits phorbol ester-induced expression of COX-2 and activation of NF-kappaB in mouse skin by blocking IkappaB kinase activity. Carcinogenesis. 2006; 27: 1465-74.

134. Candelario-Jalil E, de Oliveira AC, Gräf S, Bhatia HS, Hüll M, Muñoz E, et al. Resveratrol potently reduces prostaglandin E2 production and free radical formation in lipopolysaccharide-activated primary rat microglia. J Neuroinflammation. 2007; 4: 25.

135. Kim YA, Kim GY, Park KY, Choi YH. Resveratrol inhibits nitric 
oxide and prostaglandin E2 production by lipopolysaccharideactivated C6 microglia. J Med Food. 2007; 10: 218-24.

136. Sharma S, Chopra K, Kulkarni SK, Agrewala JN. Resveratrol and curcumin suppress immune response through CD28/CTLA-4 and CD80 co-stimulatory pathway. Clin Exp Immunol. 2007; 147: 15563.

137. Singh NP, Hegde VL, Hofseth LJ, Nagarkatti M, Nagarkatti P. Resveratrol (trans-3,5,4'-tri-hydroxystilbene) ameliorates experimental allergic encephalomyelitis, primarily via induction of apoptosis in $\mathrm{T}$ cells involving activation of aryl hydrocarbon receptor and estrogen receptor. Mol Pharmacol. 2007; 72: 1508-21.

138. Bertelli A, Falchi M, Dib B, Pini E, Mukherjee S, Das DK. Analgesic resveratrol? Antioxid Redox Signal. 2008; 10: 403-4.

139. Parker JA, Arango M, Abderrahmane S, Lambert E, Tourette $\mathrm{C}$, Catoire $\mathrm{H}$, et al. Resveratrol rescues mutant polyglutamine cytotoxicity in nematode and mammalian neurons. Nat Genet. 2005; 37: 349-50.

140. Marambaud P, Zhao H, Davies P. Resveratrol promotes clearance of Alzheimer's disease amyloid-beta peptides. J Biol Chem. 2005; 280: $37377-82$.

141. Karlsson J, Emgard M, Brundin P, Burkitt MJ. Trans-resveratrol protects embryonic mesencephalic cells from tert-butyl hydroperoxide: electron paramagnetic resonance spin trapping evidence for a radical scavenging mechanism. J Neurochem. 2000; 75: $141-50$.

142. Da-Pan A, Blanc S, Aujard F. Resveratrol suppresses body mass gain in a seasonal non-human primate model of obesity. BMC Physiol. 2010; 10: 11. doi: 10.1186/1472-6793-10-11.

143. Da-Pan A, Terrien J, Pifferi F, Botalla R, Hardy I, Marchal J, et al. Caloric restriction or resveratrol supplementation and ageing in a non-human primate: first-year outcome of the RESTRIKAL study in Microcebus murinus. Age (Dordr). 2011; 33: 15-31.

144. Thompson MM, Jones L, Nasim A, Sayers RD, Bell PR. Angiogenesis in abdominal aortic aneurysms. Eur J Vasc Endovasc Surg. 1996; 11: 464-9.

145. Norata GD, Marchesi P, Passamonti S, Pirillo A, Violi F, Catapano AL. Anti-inflammatory and anti-atherogenic effects of cathechin, caffeic acid and trans-resveratrol in apolipoprotein $\mathrm{E}$ deficient mice. Atherosclerosis. 2007; 191: 265-71.

146. Kaneko H, Anzai T, Morisawa M, Kohno T, Nagai T, Anzai A, et al. Resveratrol prevents the development of abdominal aortic aneurysm through attenuation of inflammation, oxidative stress, and neovascularization. Atherosclerosis. 2011; 217: 350-7.

147. Patel KR, Scott E, Brown VA, Gescher AJ, Stewad WP, Brown K. Clinical Trials of resveratrol. Ann NY Acad Sci. 2011; 1215: 161-9.

148. Rutanen J, Yaluri N, Modi S, Pihlajamäki J, Vänttinen M, Itkonen $\mathrm{P}$, et al. SIRT1 mRNA expression may be associated with energy expenditure and insulin sensitivity. Diabetes. 2010; 59: 829-35.

149. Beher D, Wu J, Cumine S, Kim KW, Lu SC, Atangan L, et al. Resveratrol is not a direct activator of SIRT1 enzyme activity. Chem Biol Drug Des. 2009; 74: 619-24.

150. Kaeberlein M, McVey M, Guarente L. The SIR2/3/4 complex and SIR2 alone promote longevity in Saccharomyces cerevisiae by two different mechanisms. Genes Dev. 1999; 13: 2570-80.

151. Baur JA. Resveratrol, sirtuins, and the promise of a DR mimetic. Mech Ageing Dev. 2010; 131: 261-9.

152. Pearson KJ, Baur JA, Lewis KN, Peshkin L, Price NL, Labinskyy $\mathrm{N}$, et al. Resveratrol delays age-related deterioration and mimics transcriptional aspects of dietary restriction without extending life span. Cell Metab. 2008; 8: 157-68.
153. Barger JL, Kayo T, Vann JM, Arias EB, Wang J, Hacker TA, et al. A low dose of dietary resveratrol partially mimics caloric restriction and retards aging parameters in mice. PLoS One. 2008; 3: e2264. doi: 10.1371/journal.pone.0002264.

154. Borra MT, Smith BC, Denu JM. Mechanism of human SIRT1 activation by resveratrol. J Biol Chem. 2005; 280: 17187-95.

155. Kaeberlein M, McDonagh T, Heltweg B, Hixon J, Westman EA, Caldwell SD, et al. Substrate-specific activation of sirtuins by resveratrol. J Biol Chem. 2005; 280: 17038-45.

156. Dasgupta B, Milbrandt J. Resveratrol stimulates AMP kinase activity in neurons. Proc Natl Acad Sci USA. 2007; 104: 7217-22.

157. Feige JN, Lagouge M, Canto C, Strehle A, Houten SM, Milne JC, et al. Specific SIRT1 activation mimics low energy levels and protects against diet-induced metabolic disorders by enhancing fat oxidation. Cell Metab. 2008; 8: 347-58.

158. Park CE, Kim MJ, Lee JH, Min BI, Bae H, Choe W, et al. Resveratrol stimulates glucose transport in $\mathrm{C} 2 \mathrm{C} 12$ myotubes by activating AMP-activated protein kinase. Exp Mol Med. 2007; 39: 222-9.

159. Zini R, Morin C, Bertelli A, Bertelli AA, Tillement JP. Effects of resveratrol on the rat brain respiratory chain. Drugs Exp Clin Res. 1999; 25: 87-97.

160. Hawley SA, Ross FA, Chevtzoff C, Green KA, Evans A, Fogarty S, et al. Use of cells expressing gamma subunit variants to identify diverse mechanisms of AMPK activation. Cell Metab. 2010; 11: $554-65$.

161. Suchankova G, Nelson LE, Gerhart-Hines Z, Kelly M, Gauthier MS, Saha AK, et al. Concurrent regulation of AMP-activated protein kinase and SIRT1 in mammalian cells. Biochem Biophys Res Commun. 2009; 378: 836-41.

162. Um JH, Park SJ, Kang H, Yang S, Foretz M, McBurney MW, et al. AMP-activated protein kinase-deficient mice are resistant to the metabolic effects of resveratrol. Diabetes. 2010; 59: 554-63.

163. Canto C, Auwerx J. AMP-activated protein kinase and its downstream transcriptional pathways. Cell Mol Life Sci. 2010; 67: 3407-23.

164. Canto C, Auwerx J. Caloric restriction, SIRT1 and longevity. Trends Endocrinol Metab. 2009; 20: 325-31.

165. Yuen DA, Zhang Y, Thai K, Spring C, Chan L, Guo X, et al. Angiogenic dysfunction in bone marrow-derived early outgrowth cells from diabetic animals is attenuated by SIRT1 activation. Stem Cells Transl Med. 2012; 1: 921-6.

166. Liu B, Ghosh S, Yang X, Zheng H, Liu X, Wang Z, et al. Resveratrol rescues SIRT1-dependent adult stem cell decline and alleviates progeroid features in laminopathy-based progeria. Cell Metab. 2012; 16: 738-50.

167. Bemis JE, Vu CB, Xie R, Nunes JJ, Ng PY, Disch JS, et al. Discovery of oxazolo[4,5-b]pyridines and related heterocyclic analogs as novel SIRT1 activators. Bioorg Med Chem Lett. 2009; 19: 2350-3.

168. Milne JC, Lambert PD, Schenk S, Carney DP, Smith JJ, Gagne DJ, et al. Small molecule activators of SIRT1 as therapeutics for the treatment of type 2 diabetes. Nature. 2007; 450: 712-6.

169. Vu CB, Bemis JE, Disch JS, Ng PY, Nunes JJ, Milne JC, et al. Discovery of imidazo[1,2-b]thiazole derivatives as novel SIRT1 activators. J Med Chem. 2009; 52: 1275-83.

170. Qin W, Yang T, Ho L, Zhao Z, Wang J, Chen L, et al. Neuronal SIRT1 activation as a novel mechanism underlying the prevention of Alzheimer disease amyloid neuropathology by calorie restriction. J Biol Chem. 2006; 281: 21745-54.

171. Yang T, Chan NY, Sauve AA. Syntheses of nicotinamide riboside and derivatives: effective agents for increasing nicotinamide adenine dinucleotide concentrations in mammalian cells. J Med Chem. 2007; 50: 6458-61. 